\title{
Ophthalmic surgical elderly patient access to health care
}

\section{Introduction}

Aging is a transverse reality in the surgical population.

Elderly access to health care requires specific strategies aimed at autonomy.

\section{Objective}

To identify difficulties in accessibility to health care for elderly ophthalmologic patients.

\section{Material and Methods}

Prospective, descriptive / analytical study. Executed between July and October 2017.

Interview by phone to ophthalmologic surgical patients aged $\geq 65$ years.

\section{Working instruments:}

* 6-item Cognitive Impairment Test (6CIT) 1 : : Comprised of 6 simple, noncultural questions that do not require complex interpretation; scores from 0 to 28. Lower values indicate lower cognitive compromise and vice versa. Cut-off value for Portuguese population is 11.

* Geriatric Depression Scale (GDS15)2: Composed of 15 items, YES / NO response to evaluate presence of depression. Assume 0-4: normal; 5-10: suggestive of depression; 10-15: almost always indicative of depression

* Accessibility questionnaire: questions about physical barriers in the access to the hospital and the service and availability / quality of the information received.

Sociodemographic data - age, gender, schooling, family and domestic situation, residence and previous illness.

Excluded: patients from urgent surgery, who refused to participate and with cognitive impairment $(6 \mathrm{CIT} \geq 11)$.

SPSS $尺$ V.23 for statistical analysis. Significance level with $p<0.05$.

\section{Results}

\begin{tabular}{|c|c|c|c|}
\hline Included & & & \\
\hline & 773 & Did not attend & \\
\hline 1195 & 91 & Refused & \multirow{2}{*}{307} \\
\hline & 24 & 6 CIT $\geq 11$ & \\
\hline 307 & Answered & \\
\hline
\end{tabular}

Table 1. Patient selection

\begin{tabular}{|c|c|}
\hline Score GDS15 & $\%$ \\
\hline $0-4$ & 80,5 \\
\hline $5-10$ & 14,3 \\
\hline $11-15$ & 5,2 \\
\hline
\end{tabular}

Table 3. Results of GDS15

\begin{tabular}{|c|c|}
\hline \multicolumn{2}{|c|}{ Sociodemographic data $(\mathrm{n}=307)$} \\
\hline Age (mean \pm SD) & $75 \pm 6,22$ \\
\hline Women $(\%)$ & 51,1 \\
\hline Basic education $(\%)$ & 70,4 \\
\hline Married (\%) & 78,8 \\
\hline Lives Accompanied (\%) & 87 \\
\hline Rural (\%) & 63,2 \\
\hline Table 2. Sociodemographic data \\
\hline Health status information ( $n=307$ ) \\
\hline Previous Illness (\%) & 80,5 \\
\hline Table 4. Health status information \\
\hline
\end{tabular}

\begin{tabular}{|l|l|l|l|}
\hline & \multicolumn{2}{|c|}{ ACCESSIBILITY } & \\
\hline Difficult parking (\%) & 52,8 & Use of elevators (\%) & 90,9 \\
\hline Distant parking (\%) & 52,4 & Good service signaling (\%) & 90,2 \\
\hline Lack of waiting room capacity (\%) & 61,9 & Professionals availability (\%) & 84,7 \\
\hline Missing seats in waiting room (\%) & 62,9 & Quality of information provided (\%) & 90,9 \\
\hline & & Understanding of information received (\%) & 89,3 \\
\hline
\end{tabular}

Table 5. Results of accessibility questionnaire

\section{Conclusion}

- Factors limiting health care were identified, namely in terms of proximity and facilities.

- In general, patients are satisfied with the availability and suitability of health services and information.

Bibliographic references

1.Paiva, Diana S; Apóstolo, João L. A. 2015. Estudo de adaptação transcultural e validação do Six Item Cognitive Impairment Test. In J. Apóstolo \& M. Almeida (Eds). Elderly Health Care Nursing. Monographic Series - Health Sciences Education and Research, 3 -18.

2.Greenberg SA. The Geriatric Depression Scale(GDS). Hartford Institute for Geriatric Nursing, NYU College of Nursing, n4, 2012 